TITLE:

\title{
Numerical modelling of fluid flow tests in a rock fracture with a special algorithm for contact areas
}

$\operatorname{AUTHOR}(S):$

Koyama, T.; Li, B.; Jiang, Y.; Jing, L.

\section{CITATION:}

Koyama, T....[et al]. Numerical modelling of fluid flow tests in a rock fracture with a special algorithm for contact areas. Computers and Geotechnics 2009, 36(1-2): 291-303

\section{ISSUE DATE:}

2009-01

URL:

http://hdl.handle.net/2433/93461

\section{RIGHT:}

Copyright @ 2008 Elsevier; この論文は出版社版でありません。引用の 際には出版社版をご確認ご利用ください。; This is not the published version. Please cite only the published version. 


\title{
Numerical modelling of fluid flow tests in a rock fracture with a special algorithm for contact areas
}

\author{
T. Koyama ${ }^{a^{*}}$, B. Li ${ }^{b}$, Y. Jiang ${ }^{b}$ and L. Jing ${ }^{a}$
}

${ }^{a}$ Engineering Geology and Geophysics Research Group, Department of Land and Water Resources Engineering, Royal Institute of Technology, KTH, S-100 44, Stockholm, Sweden

${ }^{\mathrm{b}}$ Faculty of Engineering, Nagasaki University, Nagasaki, 852-8521, Japan

* Corresponding author.

Tomofumi Koyama

Engineering Geology and Geophysics Research Group,

Department of Land and Water Resources Engineering,

Royal Institute of Technology, KTH,

S-100 44 Stockholm, Sweden.

Tel.: +46-8-790 6807

Fax: $+46-8-7906810$

E-mail address: tomofumi@kth.se (T. Koyama)

Submitted to Computers and Geotechnics on the 22nd of January, 2007 


\begin{abstract}
The fluid flow in rock fractures during shear processes has been an important issue in rock mechanics and is investigated in this paper using Finite Element Method (FEM), considering evolutions of aperture and transmissivity with shear displacement histories under different normal stress and normal stiffness conditions as measured during laboratory coupled shear-flow tests. The distributions of fracture aperture and its evolution during shearing were calculated from the initial aperture, based on the laser-scanned sample surface roughness results, and shear dilations measured in the laboratory tests. Three normal loading conditions were adopted in the tests: simple normal stress and mixed normal stress and normal stiffness to reflect more realistic in situ conditions. A special algorithm for treatment of the contact areas as zero-aperture elements was used to produce more accurate flow field simulations, which is important for continued simulations of particle transport but often not properly treated in literature. The simulation results agree well with the measured hydraulic apertures and flow rate data obtained from the laboratory tests, showing that complex histories of fracture aperture and tortuous flow fields with changing normal loading conditions and increasing shear displacements. With the new algorithm for contact areas, the tortuous flow fields and channeling effects under normal stress/stiffness conditions during shearing were more realistically captured, which is not possible if traditional techniques by assuming very small aperture values for the contact areas were used. These findings have an important impact on the interpretation of the results of coupled hydro-mechanical experiments of rock fractures, and on more realistic simulations of particle transport processes in fractured rocks.
\end{abstract}

Keywords: Rock fractures; Coupled stress-flow tests; shear displacement; normal loading; contact areas; Finite Element Method (FEM) 


\section{Introduction}

Coupled stress-flow processes in rock fractures are increasingly important research topics for the development and utilizations of deep underground spaces such as radioactive waste repositories, geothermal energy extractions and petroleum reservoirs. The performance of these facilities depends on the knowledge of permeability of rock masses, which varies with in situ and disturbed stress conditions and the hydro-mechanical behaviors of rock fractures. Especially for high-level radioactive waste disposal facilities in crystalline rocks, their safety assessments are mainly based on the knowledge of paths and travel times of radioactive nuclide transport that is dominated by groundwater flow in rock fractures.

As far as laboratory tests for rough rock fractures are concerned, laboratory studies focusing on the effect of both normal and shear stresses on fluid flow through rock fractures, so-called coupled shear-flow tests, have been a particular attraction due to its importance to understand and quantify the coupled stress-flow processes in fractured rocks [1-7]. In laboratory direct shear tests, the constant normal loading/stress (CNL) condition corresponds to the cases such as non-reinforced rock slopes. For deep underground opening or rock anchor-reinforced slopes, more representative in situ condition of rock fractures would be the one under constant normal stiffness (CNS) condition [8,9]. Many of the coupled shear-flow tests have been performed under CNL condition and some new tests under CNS condition have been reported recently $[2,6-7]$.

Many efforts have also been made to test fluid flow and tracer transport processes in rock fractures, with or without flow visualization and normal stress [10-13]. It was found that fluid flows in rock fractures through connected and tortuous channels that bypass the contacts areas. However, the effects of contacts and the channel distribution patterns on the fluid flow and tracer transport processes in a rock fracture and their change due to both normal and shear 
displacements/stresses have not been fully understood. This is mainly due to the difficulties of quantitative measurements of changing fracture surface roughness and aperture during laboratory coupled stress-flow tests, especially the contact areas, as well as a number of technical difficulties exist in laboratory shear-flow testing, most notably the sealing of fluid during shear.

Flow simulations in rough fractures are often performed considering effects of only normal stress $[14,15]$ or small shear displacements without normal stress or with only very small normal stresses [16-19], under well controlled hydraulic gradients. The Reynolds equation is commonly applied to simulate such tests instead of the Navier-Stokes equation. How to measure or calculate the fracture aperture under different normal stresses and shear displacements during the coupled stress-flow tests and numerical simulations are the most essential points to understand the process, interpret the testing and simulation results and quantify the hydraulic properties. The important phenomenon of shear induced anisotropy and heterogeneity of aperture distribution and its effects on fluid flow in fractures, such as the more significant flow in the direction perpendicular to the shear, was reported in [16-19]. These findings represent an important step for more physically meaningful understanding of the coupled shear-flow processes in rock fractures. However in these works, due to numerical difficulties, very small aperture values were assigned to contact areas to avoid solving ill-formed matrix equations $[17,20-21]$. Therefore, there still exist some flow inside the contact areas, even they are small in magnitudes. Such treatment of contact areas as non-zero aperture elements is not only physically nonrealistic, but may have more significant effects on the particle transport simulations since such fluid-conducting contact areas will change the particle transport paths, which may affect the estimations of travel time, dispersivity and tortuosity. The work presented in [14] is the only case to treat contact areas correctly but they did not consider the effects of shear displacement. 
In the present study, laboratory tests of fluid flow in three fracture replicas under different normal stresses and stiffness conditions were simulated by using numerical simulations with FEM, considering simulated evolutions of aperture and transmissivity with large shear displacements. The distributions of fracture aperture and its evolution during shearing and the flow rate were calculated from the initial aperture and shear dilations and compared with results measured in the laboratory coupled shear-flow tests. The contact areas in the fractures were treated correctly with zero aperture values with a special algorism so that more realistic flow velocity fields and potential particle paths were captured, which is important for continued works on more realistic simulations of particle transport to be reported separately later.

\section{The experimental study}

\subsection{Sample preparations}

A natural rock fracture surface, labeled J3, were taken from the construction site of Omaru power plant in Miyazaki prefecture in Japan and used as the parent fracture surface in this study as shown in Fig. 1. This natural fracture surface is quite rough $(\mathrm{JRC}=16-18)$ without major structural non-stationarities. Three replicas of fracture specimens were manufactured with the $\mathrm{J} 3$ as the parent fracture surface. The specimens are $100 \mathrm{~mm}$ in width, $200 \mathrm{~mm}$ in length and $100 \mathrm{~mm}$ in height, respectively. They were made of mixtures of plaster, water and retardant with weight ratios of 1: $0.2: 0.005$. The surfaces of the natural rock fractures were firstly re-cast by using resin, and then the two parts of a fracture specimen were manufactured based on the resin replica. By doing so, the two parts of each fracture specimens used in this 
study are almost perfectly mated as the initial condition with contact ratio very close to 1.0 [6-9].

2.2 Fracture surface measurement

A three-dimensional laser scanning profilometer system with an accuracy of $\pm 20 \mu \mathrm{m}$ and a resolution of $10 \mu \mathrm{m}$ was employed to obtain the topographical data of rock fracture surface $\mathrm{J} 3$. A $\mathrm{X}-\mathrm{Y}$ positioning table is added to the laser scanner, which can move automatically by pre-programmed paths, together with a PC computer performing data collecting and processing in real time. The surface of $\mathrm{J} 3$ was measured with an interval of $0.2 \mathrm{~mm}$ in both $x$ and $y$-axes [6-9].

\subsection{Coupled shear-flow tests under CNL and CNS conditions}

A series of coupled shear-flow tests under constant normal stresses (CNL) and constant normal stiffness (CNS) conditions (with initial normal stresses) were carried out using the newly developed apparatus in Nagasaki University, Nagasaki, Japan [6, 7]. The normal stress/stiffness conditions applied during the tests are summarized in Table 1. The increase of normal stress due to application of normal stiffness was automatically determined and added by the LABVIEW software of the servo-controlled test apparatus.

The flow rates were measured during the shear-flow tests with a constant hydraulic head difference of $0.1 \mathrm{~m}$ during shear, with a $1 \mathrm{~mm}$ interval of shear displacement up to $18 \mathrm{~mm}$. The flow direction is parallel with the shear direction. Since the sizes of the upper and lower 
parts of the specimens are the same, the actual contact lengths decrease during shear. As a result, the hydraulic gradient was not constant (became progressively larger) during shear so that the back-calculations of flow rates and hydraulic conductivities were adjusted to this condition. The details about features of the coupled shear-flow testing apparatus and testing procedure were reported in [6-9].

\subsection{Evaluation of aperture evolution during shear-flow tests}

The aperture (or transmissivity) and its evolution during shear are key issues for simulating fluid flow and mass transport in rock fractures. In common practice, the mean transmissivity or hydraulic aperture of a sample can be calculated from measured flow rate from which the mean aperture is back-calculated by assuming the validity of the cubic law. The detailed distribution of aperture/transmissivity inside the fracture cannot be directly measured during shear tests, but could be accurately simulated by numerical simulations if the topographical data of the fracture surfaces are available. A previous work on evolution of aperture distributions inside a rock fracture during shear-flow coupling tests simulated using a FEM code is reported in [18], based on the measured topographical data of fracture surfaces.

During the shear-flow tests, the mean mechanical aperture, $b_{m}$, was assessed based on measured values of the items in the following equation [1]:

$$
b_{m}=b_{0}-\Delta b_{n}+\Delta b_{s}
$$

where $b_{0}$ is the initial aperture, $\Delta b_{n}$ is the change of aperture by normal loading (such as closure or opening), and $\Delta b_{s}$ is the change of aperture by shearing (dilation). The initial aperture $b_{0}$ under a certain normal stress can be obtained by using the normal stress-normal 
displacement curves (which are usually fitted by a hyperbolic function) when initial stress state is available. Under the CNL boundary conditions, $\Delta b_{n}$ could be taken as a constant, and $\Delta b_{s}$ is the measured normal displacement (dilation) during shear. For the tests under the CNS boundary conditions, the normal stress changes with both the normal and shear displacements, therefore, $\Delta b_{n}$ itself should be revised due to the corresponding normal stress during shear and $\Delta b_{s}$ is also the measured normal displacement (shear dilation). The evaluated mean normal displacement of the sample during shear is then used in the numerical simulations for evaluating shear-induced changes of mechanical apertures of elements in the FEM models.

The mean mechanical apertures calculated from measured topographical data using Eq.(1) and the back-calculated hydraulic aperture from experimental flow fate data using cubic law for fracture sample $\mathrm{J} 3$ under different normal loading conditions (a constant normal stress of 1.0 MPa for J3-1, normal stiffness of $0.2 \mathrm{GPa} / \mathrm{m}$ with an initial normal stress of $1.0 \mathrm{MPa}$ for J3-2 and normal stiffness of $0.5 \mathrm{GPa} / \mathrm{m}$ with an initial stiffness of $1.0 \mathrm{MPa}$ for J3-3, respectively) are compared in Table 2 and Fig. 2. Both the mean mechanical aperture and the back calculated hydraulic aperture increase with increasing shear displacements (due to the shear dilation) and decreases with increasing normal stresses, respectively. However the mean mechanical aperture is always larger than the hydraulic aperture. This is due to the fact that fluid flow occurs only in connected voids bypassing contact areas. This agrees well with commonly adopted physical behaviour of rough rock fractures. Note that when normal stiffness is applied, normal stress will increase with shear displacement by shear-induced normal dilation. Therefore normal stresses in J3-2 and J3-3 are not constant but increase gradually with shear displacement, and larger than the initial normal stress of $1.0 \mathrm{MPa}$ that is also the constant normal stress condition for J3-1. Therefore apertures of J3-2 and J3-3 are smaller at each shear state comparing with that of J3-1. The increased asperity deformation by 
stiffness induced normal stress increase was not considered in this study for simplicity, but will be considered in future works.

\section{Numerical simulations}

\subsection{Governing equations}

When flow velocity is low and the fracture surface geometry does not vary too abruptly the Reynolds equation can be used, instead of the full Navier-Stokes equations, to describe the flow in fractures $[16,22]$. Assuming that the flow of an incompressible fluid through the fracture follows the cubic law, in a steady state, the governing equation can be written as

$$
\frac{\partial}{\partial x}\left(T_{x x} \frac{\partial h}{\partial x}\right)+\frac{\partial}{\partial y}\left(T_{y y} \frac{\partial h}{\partial y}\right)+Q=0
$$

where $Q$ is the source/sink term (positive when fluid is flowing into the fracture), and $T_{x x}$ and $T_{y y}$ are the fracture transmissivity in $x$ - and $y$-directions, respectively. In this paper, the local transmissivity at each point is assumed to be equal in $x$ - and $y$-directions for simplicity and is defined by

$$
T_{x x}=T_{y y}=T(x, y)=\frac{\rho_{f} g b^{3}}{12 \mu},
$$

where $\mu$ is the dynamic viscosity, $\rho_{f}$ the fluid density, $g$ the gravitational acceleration, and $b$ the local fracture aperture (calculated using Eq.(1)), respectively. The local transmissivity of the fracture can be determined element by element, according to the aperture evaluation results. In this study, the density and dynamic viscosity of water at $10^{\circ} \mathrm{C}$ were used 

acceleration $\mathrm{g}=9.807 \mathrm{~m} / \mathrm{s}^{2}$.

Applying the Galerkin scheme to the Eq. (2), the discretized FEM formulation of the above governing equation becomes

$$
\sum_{m=1}^{N}\left[K^{(m)}\right]\left\{h^{(m)}\right\}=\sum_{m=1}^{N}\left\{F^{(m)}\right\}
$$

with

$$
\begin{gathered}
\left.\left[K^{(m)}\right]=\int_{S^{(m)}}\left[B^{(m)}\right]^{\mathrm{T}}\left[D^{(m)}\right] B^{(m)}\right] d S, \\
\left\{F^{(m)}\right\}=\int_{S^{(m)}}\left[N^{(m)}\right]^{\mathrm{T}} Q^{(m)} d S-\int_{L^{(m)}}\left[N^{(m)}\right]^{\mathrm{T}}\left(T \frac{\partial h}{\partial x} n_{x}+T \frac{\partial h}{\partial y} n_{y}\right) d L,
\end{gathered}
$$

where $N$ is the total number of elements, $m$ the element number, and $\left[K^{(m)}\right],\left\{h^{(m)}\right\},\left\{F^{(m)}\right\}$, $\left[N^{(m)}\right], S^{(m)}$ and $L^{(m)}$ are the local transmissivity matrix, hydraulic head vector, flux vector, shape function matrix, surface area and the boundary in which the flow rate is known for element $m$, respectively. The symbols $n_{x}$ and $n_{y}$ are the unit normal vector components to the boundary in $x$ and $y$-direction, respectively. The matrices $\left[D^{(m)}\right]$ and $\left[B^{(m)}\right]$ are defined as

$$
\begin{gathered}
{\left[D^{(m)}\right]=\left[\begin{array}{ll}
T & 0 \\
0 & T
\end{array}\right]=\left[\begin{array}{cc}
\frac{\rho_{f} g b^{(m)^{3}}}{12 \mu} & 0 \\
0 & \frac{\rho_{f} g b^{(m)^{3}}}{12 \mu}
\end{array}\right]} \\
\left\{\begin{array}{l}
\frac{\partial h}{\partial x} \\
\frac{\partial h}{\partial y}
\end{array}\right\}=\left\{\begin{array}{c}
\frac{\partial\left[N^{(m)}\right]^{\mathrm{T}}}{\partial x} \\
\frac{\partial\left[N^{(m)}\right]^{\mathrm{T}}}{\partial y}
\end{array}\right\}\left\{h^{(m)}\right\}=\left[B^{(m)}\right]\left\{h^{(m)}\right\}
\end{gathered}
$$

To solve Eq. (4), the commercial FEM software, COMSOL Multiphysics [23] was used to simulate flow processes during shear in this study. Since the number of the scanning points on 
the surface for representing the roughness and calculating the aperture is very large $(2000 \times$ 1000 points) for each sample, even though they are regularly distributed over the specimen area, the digitalized aperture fields of the fracture specimens were divided into $20000(200 \times$ 100) small square grids of an edge length of $1.0 \mathrm{~mm}$. The mean aperture of each grid zone was calculated at each shear displacement interval $(1.0 \mathrm{~mm})$. Numerical shearing is simulated by moving the upper surface by a horizontal translation of $1 \mathrm{~mm}$ in the shear direction, then uplifting by the dilation increment according to the measured mean shear dilation value at that shear interval. Since initial aperture is zero for fully mated specimens, full contact is assumed everywhere with zero aperture as the initial condition in the numerical simulations. When translational shear and dilation displacements are enforced during the numerical simulations of shearing processes as mentioned above, the previous full contact pattern is broken and some new voids and new contact areas are generated and the contact conditions and apertures must be re-evaluated for all grid zones. When a zone has its two opposing surfaces separated, it represents a void zone and its aperture is evaluated as the mean distance in the direction normal to the mean plane of the fracture. When its two opposing surfaces are just in touch or penetrate each other with negative values of contact distance, which represents a contact zone and is assigned with a zero aperture. In reality the latter represents surface damage/asperity degradation. The degree of such approximation depends much on the scanning grid mesh resolution of the fracture surface and the chosen FEM model mesh. Some compromises and simplifications must be adopted to make a reasonable size of the FEM model for flow simulations. All void zones as assumed to be parallel plate models obeying the cubic law with a constant mean aperture. Please note that in the reality of tests, perfect full contact may or may not be realized since relocation errors (putting two opposite surfaces to their assumed initial relative positions) always exist, to varying extent. 
In the numerical modeling of fluid flow, effect of gorge materials is ignored since negligible amount of gorge materials were observed during tests. Asperity deformation was not considered but damage at contact points were partially approximated by removing the overlapping parts of contacting asperities in the contact elements. Their effects on shear dilation and fluid flow are, however, reflected in the measured total flow rate and normal displacement values. Because of the fully mated initial conditions of samples, the shear-induced dilation became the only contribution mechanism to the changes of aperture and served as the controlling parameters for the evolutions of aperture/transmissivity fields. The special treatment of the contact areas for the flow simulation is described in the next section. Since irregular triangle elements were used in the COMSOL modeling for fluid flow, which is more flexible for treatment of the complex contact geometry with much finer FEM meshes around the contact areas, the regular rectangular grid aperture data evaluated using the approach described above paragraph was linearly interpolated for the triangle elements. This technique was applied to evaluate the elemental transmissivity, which can be calculated from aperture value using Eq. (3), assuming local validity of the Reynolds equation, at each shear displacement interval to simulate the fluid flow through the fracture during shear.

\subsection{Boundary conditions and the treatment of contact areas}

Unidirectional flow parallel with the shear direction was considered in the tests by fixing the initial hydraulic heads of $0.1 \mathrm{~m}$ and $0 \mathrm{~m}$ along the left- and right-hand boundaries, respectively (see Fig. 3a). This flow boundary condition is the same as the one used in the laboratory coupled shear-flow tests, which was presented in the previous works by the authors $[6,7]$. For the contact areas, once zero values are given to the aperture, all components of the 
calculated local transmissivity matrix, $\left[K^{(m)}\right]$ in Eq. (5) becomes zero and assemblage of the local transmissivity matrix becomes singular. Therefore, Eq. (4) cannot be solved without special treatment. One usually adopted numerical technique to avoid such singularities is to assign very small aperture values to the contact elements to generate non-singular transmissivity matrices [17, 20-21]. However, by giving these artificial, even very small, transmissivity values for the elements in contact areas, due to their high resistance to the fluid flow, large hydraulic head drop will occur inside the contact areas. As a result, iso-potential contour lines become very dense through them and some flow, even very small, still exists inside the contact areas. This may not affect the calculations of global hydraulic variables such as the mean flow rates. However, it may affect the local pattern of the streamlines around the contact areas and give artificial changes to the particle transport paths that may change the travel distances and time, dispersion and tortuosity. Hence, in this study, contact areas/elements were numerically eliminated from the calculation domain and their boundaries were treated as additional internal boundaries with a zero flux condition $\partial h / \partial n \equiv(\nabla h) \cdot \mathbf{n}=0$, where $\mathbf{n}$ is the outward unit normal vector, in order to satisfy conditions of no flow into or out of the contact areas [14], as shown in Fig. 3a. This processes for finding contact areas, eliminating them from the element assemblage process and treating them as internal no-flux boundaries was done automatically by using a CAD system. Once the updated calculation domain with contact areas treated as additional boundary conditions, it is straightforward to apply the geometrical and the external/internal boundary conditions in the FEM models suitable for the COMSOL code for flow simulations. One of the FEM mesh of the fracture specimen thus generated for fluid flow simulations in this study is shown in Fig. 3b. The use of irregular triangle mesh to quantify the elemental hydraulic transmissivities is explained in Section 3.1. 


\section{Results}

\subsection{Aperture, transmissivity and contact area evolutions during shear}

Figure 4 show the evolution of transmissivity fields of sample J3 under different normal loading conditions: J3-1, J3-2 and J3-3. In the figure, the white 'islands' indicate the contact areas. The grey intensity of the background in the flow areas indicates the magnitude of local transmissivities (see the legend in the figures). The simulation results show that shear induced new contact areas decrease slowly with increasing shear displacement (from full contact as the initial condition), reach a critical value at about $2 \mathrm{~mm}$ of shear displacements, decrease sharply afterwards and become almost constant after shear displacement of $5 \mathrm{~mm}$ (Fig. 4a, c), with the number of contact spots becoming much smaller and focused at a much fewer locations of larger areas of contact. Figure 5 shows the measured shear stress and normal displacement (dilation) curves during shear. The oscillations of small magnitudes in the stress curves are probably due to the interactions between the samples and testing frame, and asperity damage on the fracture sample surfaces. A good correspondence can be observed between the development stages of contact areas and the shear stress (Fig. 5a) and shear dilation curves (Fig. 5b). The critical total area of contact at a shear displacement of $2 \mathrm{~mm}$, indicating the maximum mobilized contact areas (Fig. 4), corresponds to the occurrence of the peak shear stress at the same shear displacement (Fig. 5a) and the first upward turning point of the shear dilation curve (Fig. 5b). Continuous increase of the shear dilation indicates continuous increase of the aperture, as indicated also in Fig. 2. It is important to note that at all stages the distributions of contact spots are relatively uniform, indicating the homogenization for calculating the mean values of hydraulic properties is reasonable. Such 
basis for homogenization may not exist if fractures have dominating structural non-stationarities (such as large scale asperities clustered at one or two spots).

These figures clearly show the influences of initial morphological behaviors of rock fractures and the normal loading effects on the development of transmissivity.

\subsection{Flow simulation results}

The simulated results of flow velocities are superimposed in Fig. 4, with arrows, at different shear displacement of $1,2,5$ and $10 \mathrm{~mm}$ for fracture $\mathrm{J} 3$ under different normal loading conditions (J3-1, J3-2 and J3-3, respectively). Since the samples are assumed to be fully mated with a zero initial aperture, no flow is possible at the start. At $1 \mathrm{~mm}$ of shear displacement, the contact areas are widely and uniformly distributed over the whole fracture sample with small fluid flow at a number of outlet spots without major flow path (first figure of Figs. $4 \mathrm{a}, \mathrm{b}$ and $\mathrm{c}$ ). More continuous flow paths start to form at $2 \mathrm{~mm}$ of shear displacements, and continue to grow into main flow paths with continued decrease of contact areas and increase of transmissivity, with increasing shear displacement (see the last three figures of Figs. 4a, b, and c), with only one outlet spot on the outlet boundary of the samples, with the widely distributed contact areas and complicated void space geometry, which causes complex structure of transmissivity and flow velocity fields. As a result, flow patterns (or stream lines) become very tortuous. This phenomenon is the well-known 'channelling effect' [24]. At present only numerical simulations can illustrate realistically the process of complex evolution of the flow localization (channeling) during shear under different normal loading conditions, since direct measurement and visualization is not possible. 
The flow rate at the outlet boundary (along $x=0$ ) of sample J3 with different normal loading conditions were compared between laboratory tests and numerical simulations as shown in Fig. 6 and Table 3. Note that the zero flow rates cannot be plotted in the figure with log-scaling in the axis for flow rate. The general behaviors of the simulated flow rate variations with shear displacements under different normal stress/stiffness conditions were captured for all three conditions of normal loading, agree well with measured results. Both simulated and measured flow rates show the sharp increase at about $2 \mathrm{~mm}$ shear displacements and continue to increase but with a progressive reduction of gradient, and more stabilized flow rate after the $5 \mathrm{~mm}$ shear displacement, corresponding to the almost stabilized contact areas as shown in Fig. 4. The general increase of flow rate is about 5-6 orders of magnitude from the initial state before shear. The maximum increase of flow rate is between $10^{-5}-10^{-4} \mathrm{~m}^{3} / \mathrm{sec}$ in order of magnitude. These general behaviors agree with the general understanding of the flow behavior of rock fractures. Please note that the numerical simulation was not calibrated with test results but predictions with assumptions of zero apertures (therefore zero flow rate) as the initial state for all cases. But in test, non-zero flow rate was observed in $\mathrm{J} 3-3$, with possible relocation errors that were not considered in numerical predictions.

The results presented here are more realistic, due to more proper treatment of contact areas in flow simulations, compared with earlier results reported in literature, obtained from flow simulations in which fracture samples have only a few very small contact areas, without normal stress or with very small normal stresses [16-19].

The measured hydraulic apertures of the fractures and their evolutions during shear were back calculated from the flow rates obtained from laboratory tests are compared with the predicted values by numerical simulations in Fig. 7, and tabulated in Table 4. The measured and predicted values agree well, even with non-zero initial apertures during tests. The magnitudes 
of the predicted hydraulic apertures are systematically slightly larger than the measured ones due to the fact that deformation and damage of asperities on fracture surface and generation of gorge materials were not considered in the numerical predictions so that the measured flow rates should be smaller than the simulated ones, but the discrepancy is well within acceptable small ranges corresponding to mechanical deformation/damage effects. Both the numerical predictions and the measured aperture data show that with increasing normal stresses in the order of J3-1, J3-3 and J3-2 in terms of normal stress magnitude, apertures decreases accordingly in the same order. This agrees well with commonly adopted physical behaviour of rough rock fractures. The small offset between the results in J3-2 and J3-3 are due to changes in test conditions occurred during tests (such as consistency in fluid sealing at different shear stages and initial sample relocation offsets, etc.).

The deviations in flow rates and hydraulic apertures between the experimental results and numerical predictions may be caused by three possible reasons that were not considered in numerical simulations:

1) uneven dilation in the fracture (tilting of the fracture samples, for example) during coupled shear-flow tests;

2) relocation offsets by experimental difficulties to realize fully mated initial condition with very small fluid flow still exists for J3-1 and J3-2 even after applying weak cyclic normal loading during tests (see Figs. 6 and 7 and Tables 3 and 4);

3) mechanical deformation and damage of asperities and thus generated gorge materials.

Among the above reasons as possible sources of discrepancies in the results of flow rates and hydraulic apertures, the ignorance of asperity deformation are the most significant, since generation of gorge materials by damage is not significant as observed in tests. The relocation error (offset) is of the secondary importance since it affects mainly the general behaviors of 
simulation results in early stage of shear, before $2 \mathrm{~mm}$ of shear displacement. The effects of relocation offset and tilting could be considered readily in further model calibrations as long as the initial aperture and tilting direction and extent can be quantified during testing, but the asperity deformation and damage cannot be properly considered at present.

\section{Discussions and concluding remarks}

In the present study, the fluid flow in rock fracture replicas during shear under normal stress and normal stiffness controls was simulated using the COMSOL Multiphysics code of FEM with a special algorism for contact areas, considering evolutions of aperture and transmissivity fields during shear, obtained from real coupled shear-flow tests of fracture specimens of realistic surface roughness features. The numerical models captured complex behavior of fluid flow in fracture samples with special highlights in terms of contact area evolutions using the special algorithm of contact elements of zero apertures. This contact algorithm is an important link for realistic simulations of couplings between stress and fluid flow in fractures with shear and under normal loading. The results show that such special treatment of contact areas can simulate more realistic behaviour of flow fields in fractures that is important for particle transport simulations.

Besides the above general conclusions, a few outstanding issues need to be further discussed.

a) Validity of Reynolds equation (the cubic law)

The Navier-Stokes equations have been solved using FEM in real fracture geometry, considering non-linear regimes of fluid flow in rock fractures, with results compared to experiments, as reported in [25]. The Reynolds equation, on the other hand, is more 
commonly used for the flow in fractures for its simplicity, as demonstrated by many publications, under certain conditions of hydraulic gradient, aperture, fluid velocity, etc., depending on the Reynolds number of the flow fields. We used it for simplicity in this work since effects of normal stress and shear displacement on fluid flow in fractures are the causes of first order variations and are therefore the main concern, and believed that the Reynolds equation could be acceptable for all shear displacement stages. To check whether our assumption is valid, we calculated the Reynolds numbers of the measured flow data during the tests, as listed in Table 5. The resultant Reynolds numbers generally satisfies the requirements for laminar steady state flows, as we assumed. Therefore, use of Reynolds equation for solving the flow and back-calculating the hydraulic properties can be accepted.

b) Technical difficulties of measuring evolutions of aperture during shear

The accurate knowledge of aperture evolution under normal loading during shear is important for the development of coupled hydro-mechanical constitutive models for rock fractures. To get accurate aperture values during shear, direct measurement is desirable but not possible in practice in laboratory tests at present. The most common way to obtain the mean aperture in numerical modeling is to calculate the distance of superimposed two rough surfaces in the direction perpendicular to the nominal fracture plane, which is adopted in this study, and back-calculation using measured flow rate in tests assuming validity of the cubic law. However, some assumptions are always required to determine the initial position of rough surfaces corresponding to the samples' in situ stress conditions, to quantify the local aperture distribution, and to estimate relocation errors. More accurate measurement of relocation errors at the start and quantification of tilting effects during shear are important for more accurate numerical predictions, especially for rough fracture samples not fully mated at the initial conditions. 
c) The asperity degradation/damage and generation of gorge materials cannot be measured at asperity scale directly during shear tests, due to the same technical difficulty as the determination of aperture field during shear. However, as demonstrated in this paper, they have significant effects on fluid flow in rock fractures. More development in numerical modelling with functions of stress, deformation and damage analyses are needed to improve the capacity of more reliable numerical modelling tools. On the other hand, development of more advanced experimental techniques for quantitative real-time measurement of evolution of aperture and surface roughness during shear with normal loading, in conjunction with fluid flow, however, is needed not only to validate numerical models, but also for the scientific foundation of the subject.

\section{d) Effect of proper treatment of contact areas}

The iso-value contours of hydraulic head for fracture sample $\mathrm{J} 3$ under constant normal stress of 1.0 $\mathrm{MPa}$ (test case J3-1) at a shear displacement of $5 \mathrm{~mm}$ are compared between with and without special treatment for contact areas in Fig. 8. It should be noted that very small aperture value of $0.1 \mu \mathrm{m}$ was given for the contact areas for the case of without special treatment, as shown in Fig. 8b. Figure 8a shows the results with special contact elements developed in Section 3.2. The calculated overall flow rates were almost the same between the two models. However, as shown in Fig. 8b, some of the iso-value contours of hydraulic head crossed the contact areas and caused continuous and tightly clustered zones with very small aperture values (Fig. 8b), which is physically not meaningful. Such continuous clusters will not form when zero apertures were given to contact elements (Fig. 8a), with iso-value contour lines stopping right at the boundary of the contact areas in right angles, forming a much discontinuous overall pattern of the iso-value contour lines of hydraulic head. This difference 
in the overall pattern of continuously clustered or broken clusters of iso-head contour lines will affect local stream lines around the contact areas and change the particle transport paths and travel time, such as trapping particles, and changing tortuosity of stream lines, which will affect the final calculation of break through curves and evaluation of the transport properties in the fractures [26].

\section{Acknowledgement}

The authors thank the Swedish Nuclear Power Inspectorate (SKI) for the financial support for the first author's Ph.D studies at Royal Institute of Technology (KTH), Stockholm, Sweden.

\section{References}

[1] Esaki T, Du S, Mitani Y, Ikusada K and Jing L. Development of a shear-flow test apparatus and determination of coupled properties for a single rock joint. Int J Rock Mech Min Sci 1999; 36: 641-50.

[2] Olsson R, Barton N. An improved model for hydromechanical coupling during shearing of rock joints. Int J Rock Mech Min Sci, 2001; 38: 317-329.

[3] Lee HS and Cho TF. Hydraulic characteristics of rough fractures in linear flow under normal and shear load. Rock Mech Rock Engng, 2002; 35: 299-318.

[4] Hans J and Boulon M. A new device for investigating the hydro-mechanical properties of rock joints. Int J Numer Anal Meth Geomech, 2003; 27: 513-548. 
[5] Auradou H, Drazer G, Hulin JP and Koplik J. Permeaqbility anisotropy induced by the shear displacement of rough fracture walls. Water Resour Res, 2005; 41: W09423, doi: 10.1029/2005WR003938.

[6] Li B, Jiang Y, Saho R, Tasaku Y and Tanabashi Y. An investigation of hydromechanical behaviour and transportability of rock joints. In: Rock Mechanics in Underground Construction, Proc of the 4th Asian Rock Mech Symp, eds. Leung CF Y and Zhou YX, World Scientific, 2006, pp. 321.

[7] Li B, Jiang Y, Koyama T, Jing L and Tanabashi Y. Experimental study on hydro-mechanical behaviour of rock joints by using parallel-plates model containing contact area and artificial fractures. Manuscript submitted to Int J Rock Mech Min Sci, October, 2006.

[8] Jiang Y, Xiao J, Tanabashi Y and Mizokami T. Development of an automated servo-controlled direct shear apparatus applying a constant normal stiffness condition. Int J Rock Mech Min Sci, 2004; 41(2): 275-286.

[9] Jiang Y, Li B and Tanabashi Y. Estimating the relation between surface roughness and mechanical properties of rock joints. Int J Rock Mech Min Sci, 2006; 43(6): 837-846.

[10] Brown SR, Caprihan A and Hardy R. Experimental observation of fluid flow channels in a single fracture. J Geophys Res, 1998; 103(B3): 5125-5132.

[11] Detwiler RL, Pringle SE and Glass RJ. Measurement of fracture aperture fields using transmitted light: An evaluation of measurement errors and their influence on simulations of flow and transport through a single fracture. Water Resour Res, 1999; 35(9): 2605-2617.

[12] Renshaw CE, Dadakis JS and Brown SR. Measuring fracture apertures: A comparison of methods. Geophys Res Lett, 2000; 27(2); 289-292. 
[13] Xiao J, Satou H, Sawada A and Takebe A. Visualization and quantitative evaluation of aperture distribution, fluid flow and tracer transport in a variable aperture fracture. In: Rock Mechanics in Underground Construction, Proc of the 4th Asian Rock Mech Symp, eds. Leung CF Y and Zhou YX, World Scientific, 2006, pp. 416.

[14] Zimmerman RW, Chen DW and Cook NGW. The effect of contact area on the permeability of fractures. J Hydrology, 1992; 139: 79-96.

[15] Lespinasse M and Sausse J. Quantification of fluid flow: hydro-mechanical behaviour of different natural rough fractures. J Geochemical Exploration, 2000; 60-70: 483-486.

[16] Yeo IW, De Freitas MH and Zimmerman RW. Effect of shear displacement on the aperture and permeability of rock. Int J Rock Mech Min Sci, 1998; 35: 1051-70.

[17] Kim HM, Inoue $\mathrm{J}$ and Horii $\mathrm{H}$. Flow analysis of jointed rock masses based on excavation-induced transmissivity change of rough joints. Int J Rock Mech Min Sci, 2004; 41(6): 959-974.

[18] Koyama T, Fardin N, Jing L and Stephansson O. Numerical simulation of shear induced flow anisotropy and scale dependent aperture and transmissivity evolutions of fracture replicas. Int J Rock Mech Min Sci, 2006; 43(1): 89-106.

[19] Matsuki K, Chida Y, Sakaguchi K and Glover PWJ. Size effect on aperture and permeability of a fracture as estimated in large synthetic fractures. Int J Rock Mech Min Sci, 2006; 43(5): 726-755.

[20] Brown SR. Fluid flow through rock joints: The effects of surface roughness. J Geophys Res, 1987; 92(B2): 1337-1347.

[21] Yasuhara $\mathrm{H}$ and Elsworth D. A numerical model simulating reactive transport and evolution of fracture permeability. Int J Numer Anal Meth Geomech, 2006; 30: 1039-1062. 
[22] Zimmerman RW and Bodvarsson GS. Hydraulic conductivity of rock fractures. Transp Porous Media, 1996; 23: 1-30.

[23] COMSOL AB. COMSOL Multiphysics Ver.3.3, Stockholm, 2006. Home page: http://www.comsol.se

[24] Tsang YW and Tsang CF. Channels model of flow through fractured media. Water Resour Res, 1987; 23(3): 467-479.

[25] Zimmerman RW, Al-Yaarubi A, Pain CC, and Grattoni CA. Non-linear regimes of fluid flow in rock fractures. Int J Rock Mech Min Sci, 2004; 41(3): 384-384.

[26] Koyama T, Vilarrassa V, Neretnieks I and Jing L. Shear-induced Flow Channels in a Single Rock Fracture and their Effect on Particle Transport, Manuscript submitted to Water Resour Res, March, 2006. 
Table 1. Experimental loading cases under CNL and CNS boundary conditions for sample J3.

\begin{tabular}{cccccc}
\hline \multirow{2}{*}{$\begin{array}{c}\text { Fracture } \\
\text { Samples }\end{array}$} & \multirow{2}{*}{$\begin{array}{c}\text { Loading } \\
\text { cases }\end{array}$} & $\begin{array}{c}\text { Roughness } \\
\text { (JRC range) }\end{array}$ & \multicolumn{3}{c}{ Normal loading conditions } \\
\cline { 4 - 6 } & & & ${ }^{*}$ CNL/CNS & $\begin{array}{c}\text { Initial normal stresses, } \sigma_{n i} \\
(\mathrm{MPa})\end{array}$ & $\begin{array}{c}\text { Normal stiffness, } k_{n} \\
(\mathrm{GPa} / \mathrm{m})\end{array}$ \\
\hline & & & CNL & 1.0 & 0 \\
J3 3 & $\mathrm{~J} 3-1$ & \multirow{2}{*}{$16 \sim 18$} & CNS & 1.0 & 0.2 \\
& $\mathrm{~J} 3-2$ & & CNS & 1.0 & 0.5 \\
\hline
\end{tabular}

* CNL: Constant Normal Load (stress) and CNS: Constant №rmal Stiffness

Table 2. Comparison between mean mechanical apertures and the back-calculated hydraulic apertures using the cubic law in laboratory experiments for fracture sample J3. See Table 1 for different normal loading conditions.

(unit: $\mu \mathrm{m}$ )

\begin{tabular}{rrrrrrr}
\hline \multirow{2}{*}{$\begin{array}{c}\text { Shear } \\
\text { disp. mm }\end{array}$} & \multicolumn{2}{c}{ J3-1 (CNL, 1.0 MPa) } & J3-2 (CNS, 0.2 GPa/m) & \multicolumn{2}{c}{ J3-3 (CNS, 0.5 GPa/m) } \\
\cline { 2 - 6 } & mechanical & hydraulic & mechanical & hydraulic & mechanical & hydraulic \\
\hline 1 & 119.171 & 78.0141 & 145.072 & 299.120 & 129.5993 & 0 \\
2 & 262.980 & 226.743 & 458.592 & 248.122 & 222.0791 & 55.4960 \\
3 & 519.278 & 467.933 & 742.291 & 263.580 & 423.1777 & 327.978 \\
4 & 767.296 & 578.374 & 918.687 & 399.546 & 686.6003 & 450.345 \\
5 & 950.857 & 631.659 & 1019.99 & 596.297 & 900.3918 & 552.665 \\
6 & 1153.02 & 637.699 & 1053.64 & 698.376 & 999.3655 & 654.925 \\
7 & 1285.95 & 669.418 & 1134.24 & 785.275 & 1189.439 & 728.188 \\
8 & 1381.37 & 687.352 & 1177.96 & 810.937 & 1323.947 & 794.499 \\
9 & 1451.52 & 771.911 & 1240.91 & 821.197 & 1426.133 & 889.394 \\
10 & 1524.01 & 786.980 & 1325.06 & 860.159 & 1499.285 & 813.602 \\
11 & 1607.74 & 849.646 & 1410.14 & 822.820 & 1563.727 & 817.567 \\
12 & 1668.77 & 1044.16 & 1497.07 & 840.610 & 1630.976 & 837.685 \\
13 & 1741.27 & 1019.65 & 1568.72 & 858.203 & 1687.956 & 832.306 \\
14 & 1815.91 & 1117.41 & 1611.59 & 773.331 & 1758.472 & 873.328 \\
15 & 1889.49 & 1154.70 & 1669.24 & 875.828 & 1810.214 & 921.091 \\
16 & 2004.69 & 1146.49 & 1725.01 & 853.338 & 1876.390 & 918.963 \\
17 & 2037.89 & 875.277 & 1771.20 & 871.887 & 1924.038 & 964.505 \\
18 & 2090.96 & 919.616 & 1821.15 & 970.137 & 1977.605 & 996.645 \\
\hline
\end{tabular}


Table 3. Comparison of the mean flow rates at sample outlets between laboratory experiments and numerical simulations for fracture sample J3. See Table 1 for different normal loading conditions.

(unit: $\mathrm{m}^{3} / \mathrm{sec}$ )

\begin{tabular}{rrrrrrr}
\hline \multicolumn{1}{c}{ Shear } & \multicolumn{2}{c}{ J3-1 (CNL, 1.0 MPa) } & \multicolumn{2}{c}{ J3-2 (CNS, 0.2 GPa/m) } & \multicolumn{2}{c}{ J3-3 (CNS, 0.5 GPa/m) } \\
\cline { 2 - 7 } disp. mm & Experiments & Simulation & Experiments & Simulation & Experiments & Simulation \\
\hline 0 & $3.58724 \mathrm{e}-08$ & 0 & $8.97865 \mathrm{e}-07$ & 0 & 0 & 0 \\
1 & $1.49147 \mathrm{e}-08$ & $6.81190 \mathrm{e}-09$ & $8.40683 \mathrm{e}-07$ & $2.33799 \mathrm{e}-08$ & 0 & $1.22573 \mathrm{e}-08$ \\
2 & $3.68031 \mathrm{e}-07$ & $1.10853 \mathrm{e}-07$ & $4.82259 \mathrm{e}-07$ & $1.20040 \mathrm{e}-06$ & $5.39595 \mathrm{e}-09$ & $3.40911 \mathrm{e}-08$ \\
3 & $3.25112 \mathrm{e}-06$ & $1.32808 \mathrm{e}-06$ & $5.81058 \mathrm{e}-07$ & $6.33769 \mathrm{e}-06$ & $1.11948 \mathrm{e}-06$ & $5.18847 \mathrm{e}-07$ \\
5 & $8.07910 \mathrm{e}-06$ & $1.39717 \mathrm{e}-05$ & $6.79677 \mathrm{e}-06$ & $1.31203 \mathrm{e}-05$ & $5.41128 \mathrm{e}-06$ & $7.26221 \mathrm{e}-06$ \\
7 & $9.71590 \mathrm{e}-06$ & $2.45841 \mathrm{e}-05$ & $1.56840 \mathrm{e}-05$ & $1.48290 \mathrm{e}-05$ & $1.25061 \mathrm{e}-05$ & $1.71328 \mathrm{e}-05$ \\
10 & $1.60356 \mathrm{e}-05$ & $3.78310 \mathrm{e}-05$ & $2.09378 \mathrm{e}-05$ & $1.78881 \mathrm{e}-05$ & $1.77187 \mathrm{e}-05$ & $3.52597 \mathrm{e}-05$ \\
15 & $5.20220 \mathrm{e}-05$ & $7.39862 \mathrm{e}-05$ & $2.27004 \mathrm{e}-05$ & $3.56260 \mathrm{e}-05$ & $2.64049 \mathrm{e}-05$ & $5.83768 \mathrm{e}-05$ \\
18 & $2.67115 \mathrm{e}-05$ & $1.02628 \mathrm{e}-04$ & $3.13601 \mathrm{e}-05$ & $5.02597 \mathrm{e}-05$ & $3.40015 \mathrm{e}-05$ & $7.67927 \mathrm{e}-05$ \\
\hline
\end{tabular}

Table 4. Comparison of the hydraulic apertures between laboratory measurements (from flow rates using cubic law) and numerical simulations for fracture sample J3. See Table 1 for different normal loading conditions.

(unit: $\mu \mathrm{m}$ )

\begin{tabular}{rrrrrrr}
\hline \multicolumn{1}{c}{$\begin{array}{c}\text { Shear } \\
\text { disp. mm }\end{array}$} & \multicolumn{2}{c}{ J3-1 (CNL, 1.0 MPa) } & J3-2 (CNS, 0.2 GPa/m) & \multicolumn{2}{c}{ J3-3 (CNS, 0.5 GPa/m) } \\
\cline { 2 - 7 } & Experiments & Simulation & Experiments & Simulation & Experiments & Simulation \\
\hline 0 & 104.700 & 0 & 306.265 & 0 & 0 & 0 \\
1 & 78.0141 & 60.0792 & 299.120 & 90.6252 & 0 & 73.0745 \\
2 & 226.743 & 151.992 & 248.122 & 336.264 & 55.4960 & 102.593 \\
3 & 467.933 & 347.200 & 263.580 & 584.542 & 327.978 & 253.816 \\
5 & 631.659 & 758.191 & 596.297 & 742.466 & 552.665 & 609.609 \\
7 & 669.418 & 912.195 & 785.275 & 770.738 & 728.188 & 808.746 \\
10 & 786.980 & 1047.65 & 860.159 & 816.187 & 813.602 & 1023.36 \\
15 & 1154.70 & 1298.55 & 875.828 & 1017.80 & 921.091 & 1199.93 \\
18 & 919.616 & 1440.33 & 970.137 & 1135.31 & 996.645 & 1307.62 \\
\hline
\end{tabular}

Table 5. Calculated Reynolds numbers of the flow in the test conditions of sample J3

\begin{tabular}{rccc}
\hline Shear disp. mm & J3-1 (CNL, 1.0 MPa) & J3-2 (CNS, 0.2 GPa/m) & J3-3 (CNS, 0.5 GPa/m) \\
\hline 0 & 0.27438 & 6.867605 & 0 \\
1 & 0.11408 & 6.430231 & 0 \\
2 & 2.81500 & 3.688709 & 0.041273 \\
3 & 24.8672 & 4.444403 & 8.562729 \\
5 & 61.7956 & 51.98725 & 41.38984 \\
7 & 74.3151 & 119.9642 & 95.65674 \\
10 & 122.654 & 160.1494 & 135.5272 \\
15 & 397.907 & 173.6314 & 201.9662 \\
18 & 204.311 & 239.8675 & 260.0714 \\
\hline
\end{tabular}




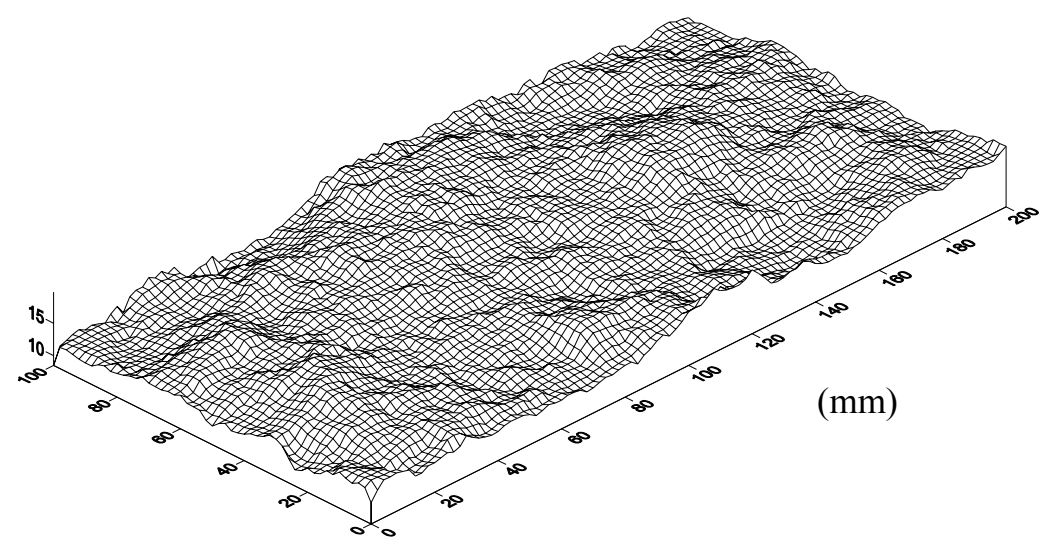

Fig. 1. 3-D surface topography model of fracture specimen $\mathrm{J} 3$ based on the laser scanning results. It should be noted that the resolution of the figures was reduced up to mesh size of 2 $\mathrm{mm}$. 


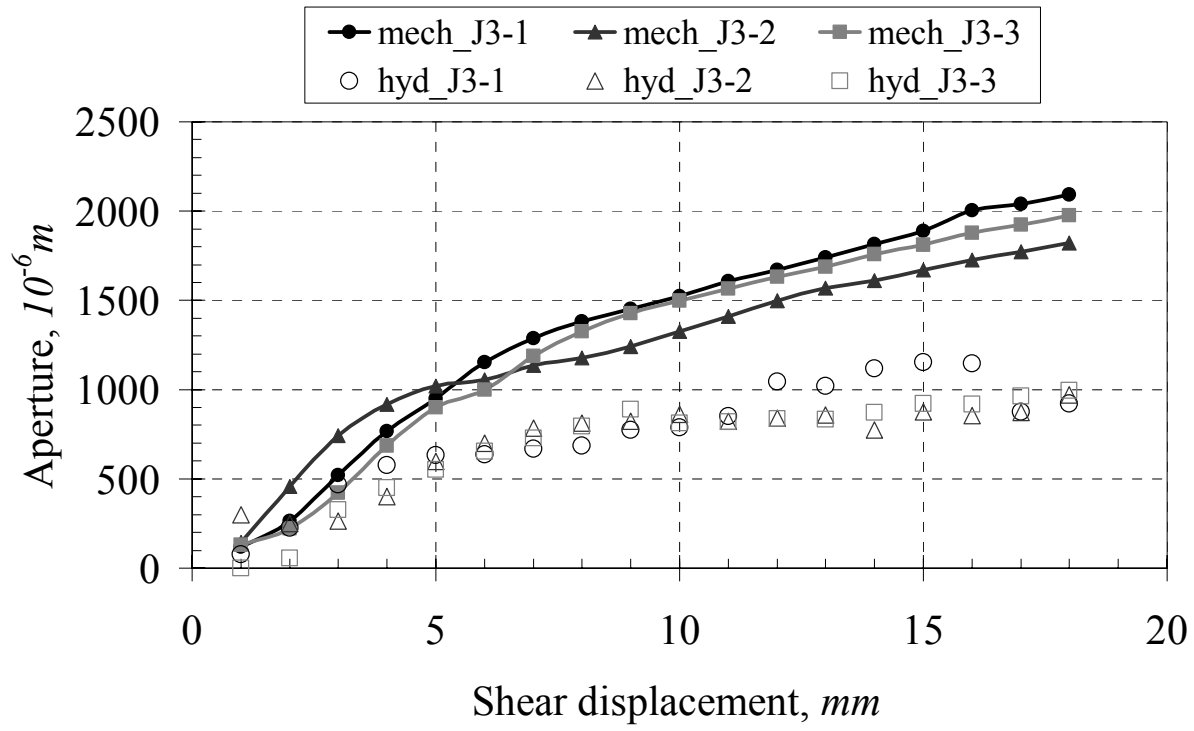

Fig. 2. Comparison between the measured mean mechanical apertures using Eq.(1) and the back-calculated hydraulic apertures from laboratory experiments using the cubic law for fracture sample J3 under different normal loading conditions J3-1, J3-2 and J3-3. 
No flow

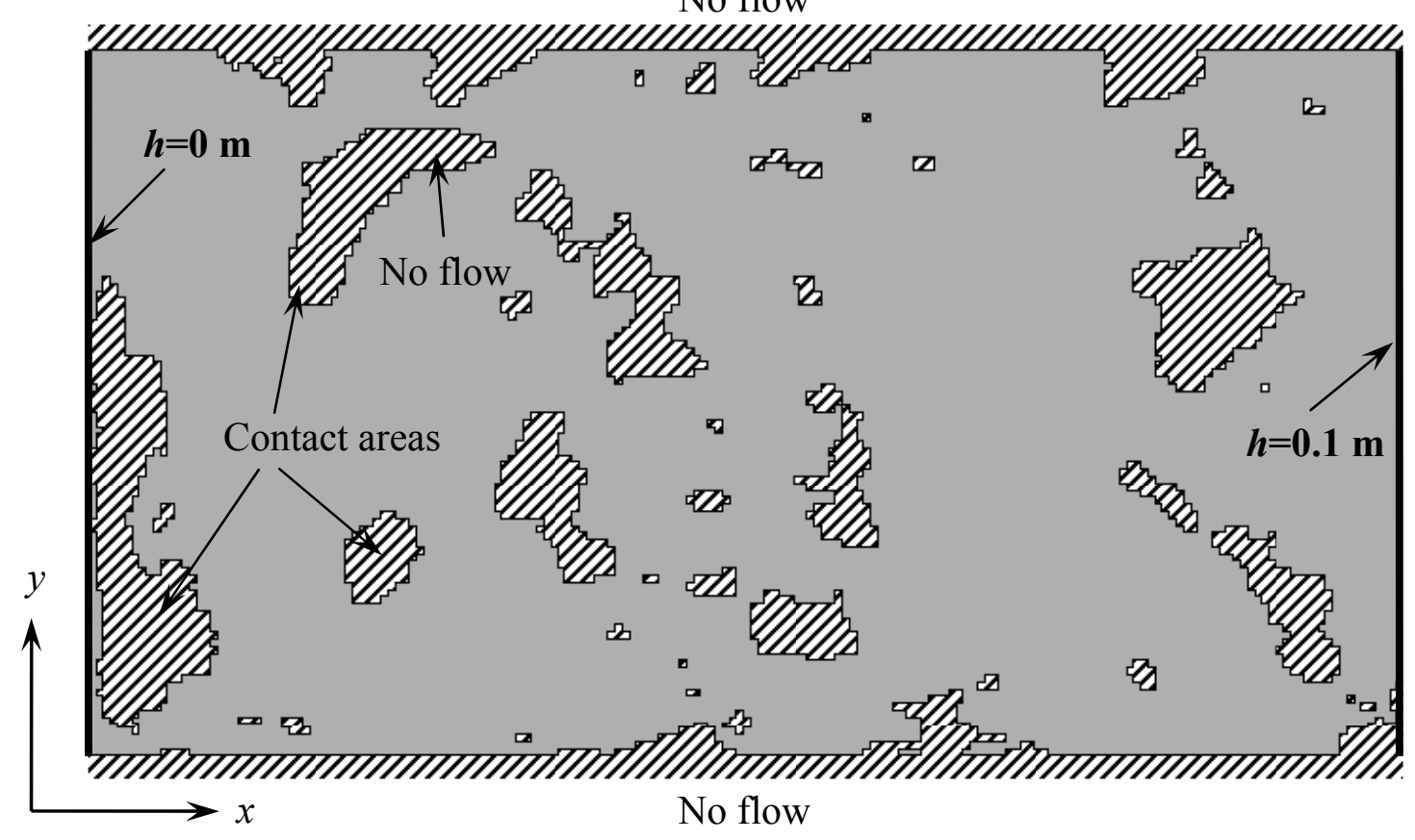

a)

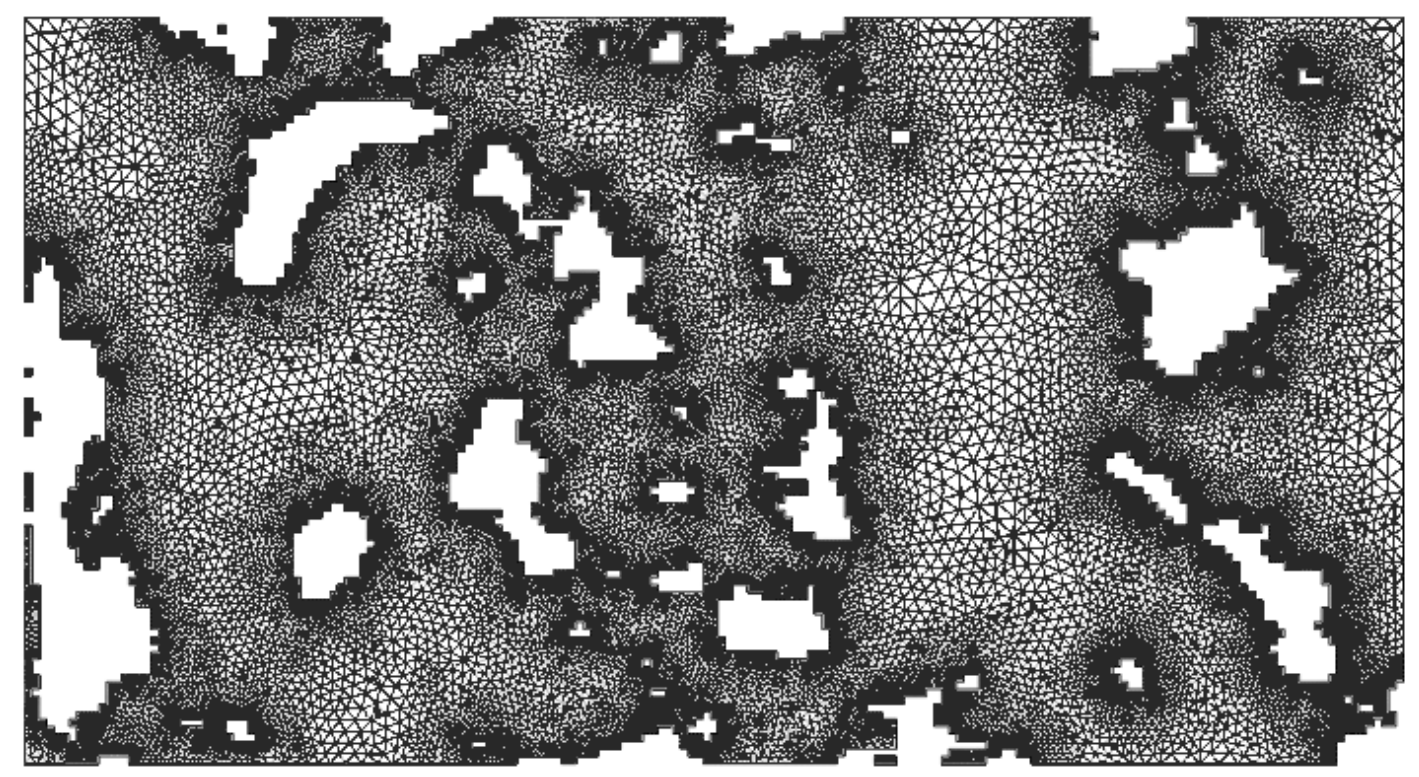

b)

Fig. 3. Special treatment for the contact areas, a) Boundary conditions for flow simulations and $b)$ the calculation mesh of a FEM model. 


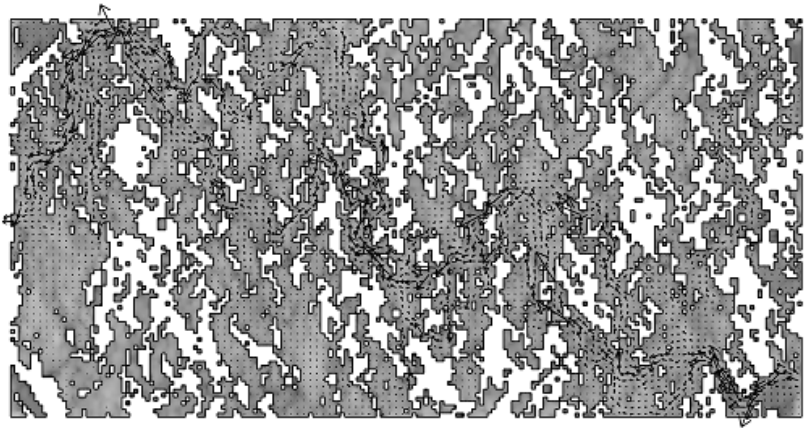

$1 \mathrm{~mm}$

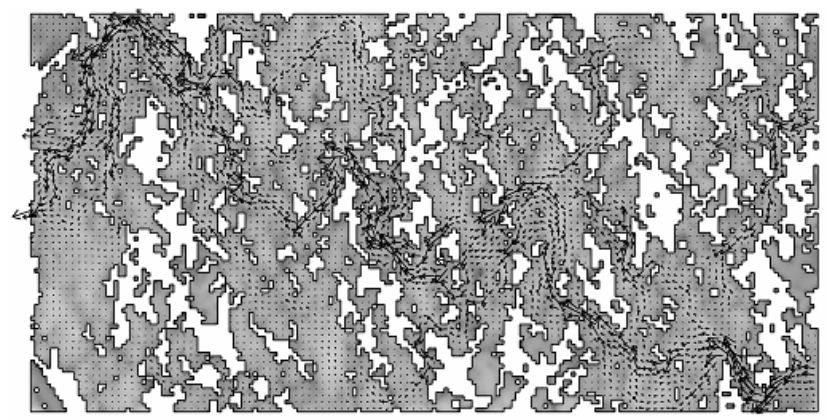

$2 \mathrm{~mm}$

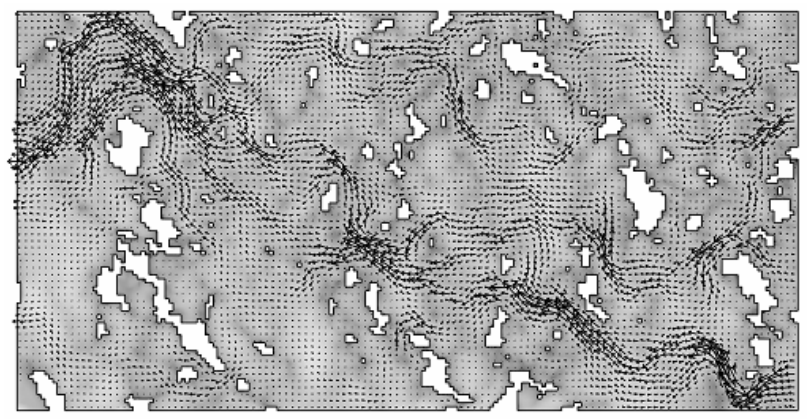

$5 \mathrm{~mm}$

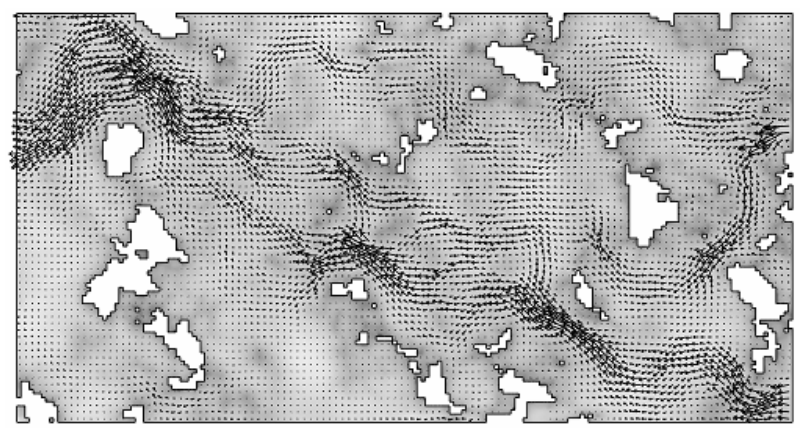

$10 \mathrm{~mm}$

a)

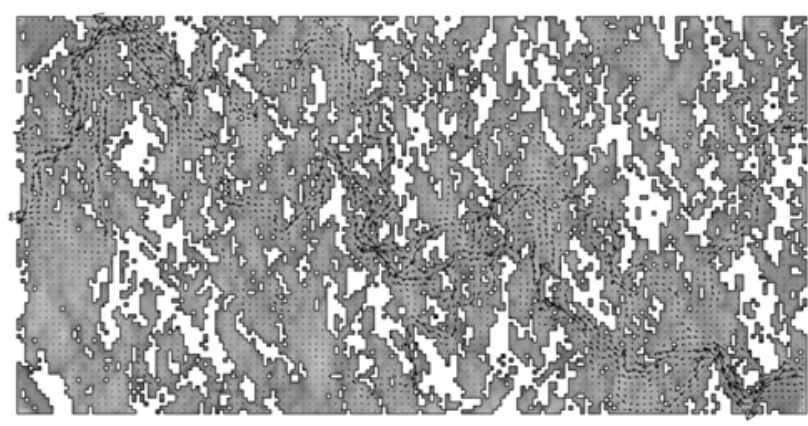

$1 \mathrm{~mm}$

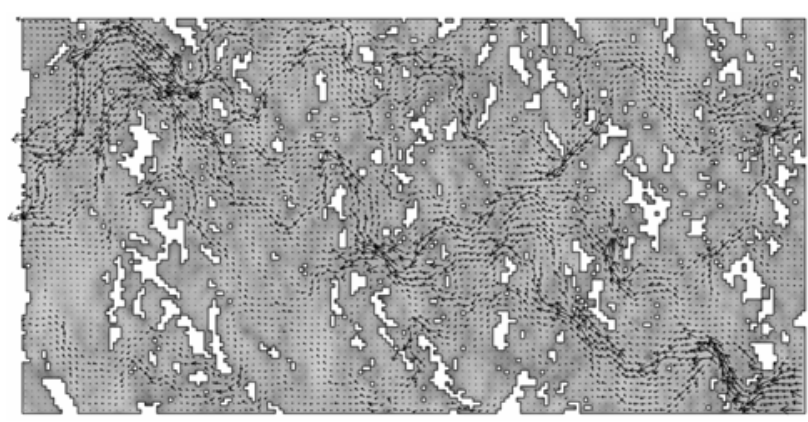

$2 \mathrm{~mm}$

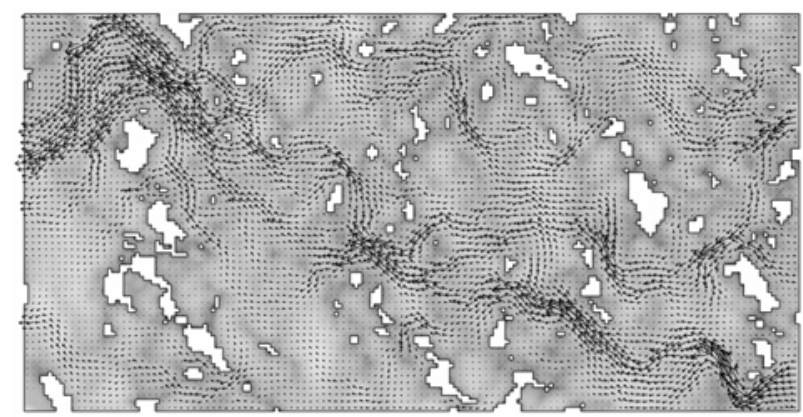

$5 \mathrm{~mm}$

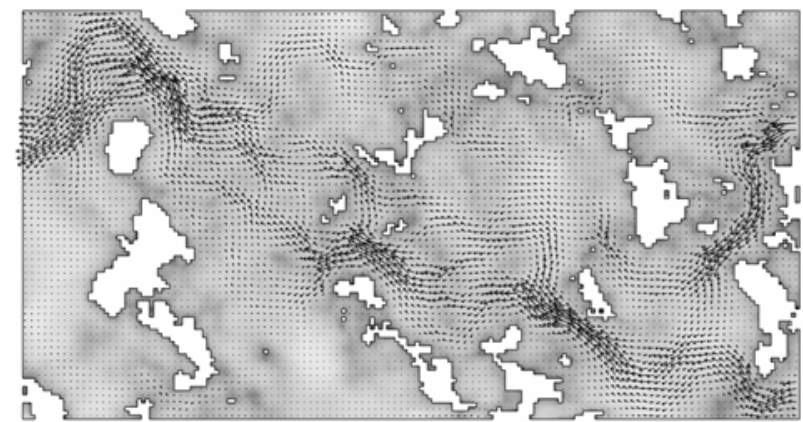

$10 \mathrm{~mm}$

b) 

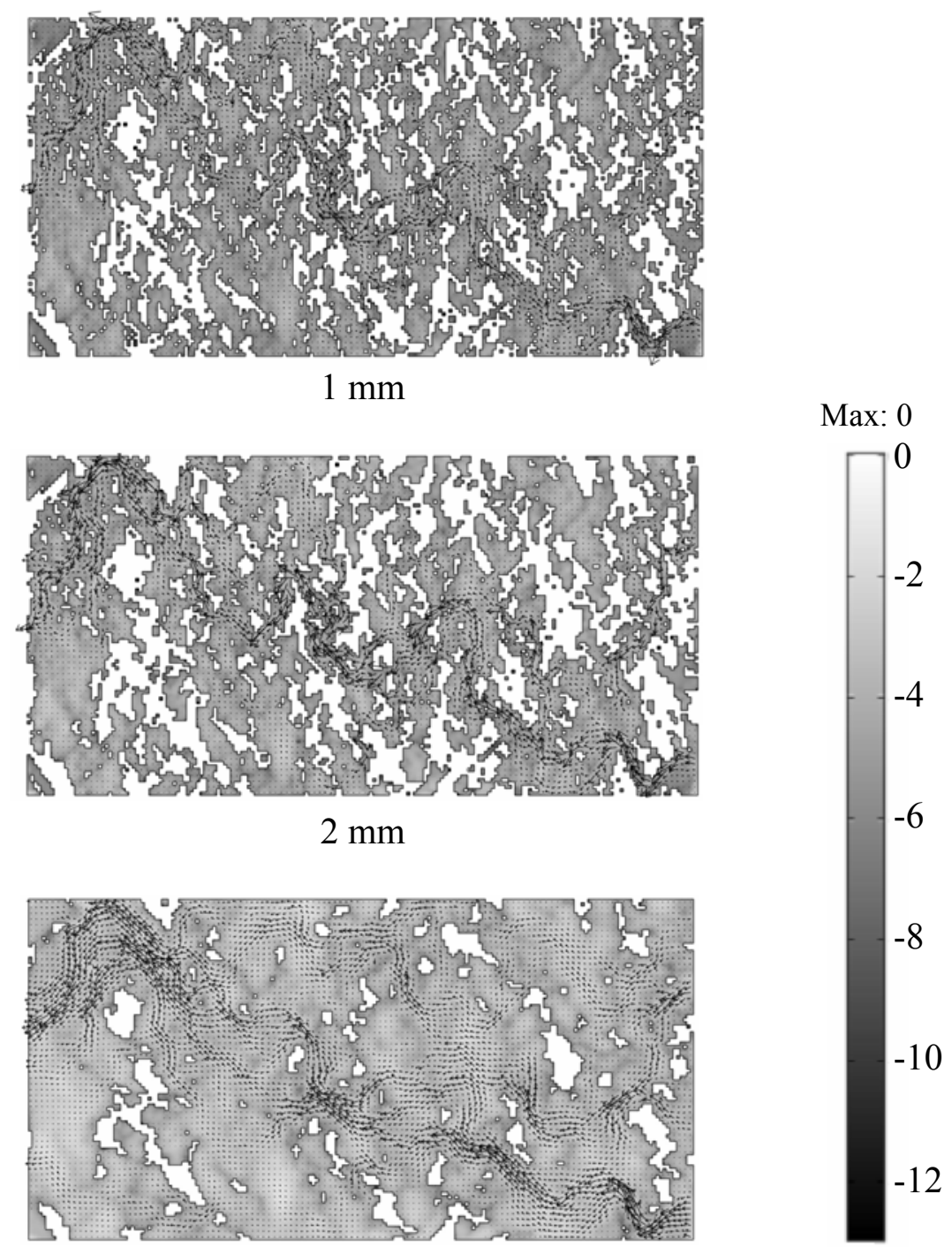

Min: -13

$5 \mathrm{~mm}$

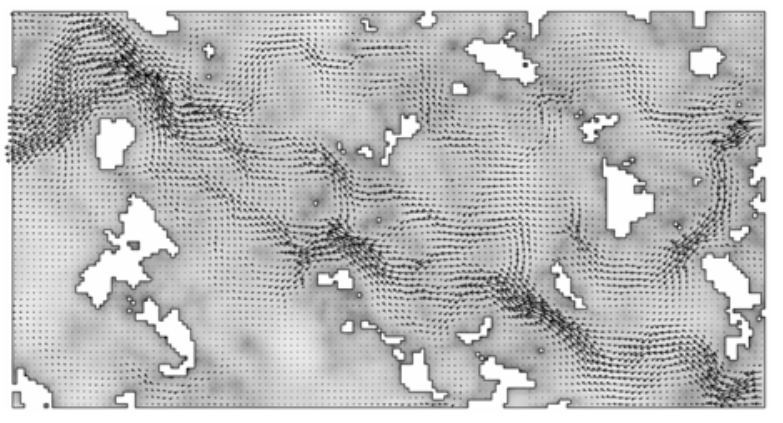

$10 \mathrm{~mm}$

c)

Fig. 4. Flow velocity fields with transmissivity evolutions at different shear displacements of 1, 2, 5 and $10 \mathrm{~mm}$ for fracture sample $\mathrm{J} 3$ under different normal loading conditions: a) constant normal stress of $1 \mathrm{MPa}, \mathrm{J} 3-1, \mathrm{~b})$ mixed initial normal stress (1.0 MPa) and normal stiffness $(0.2 \mathrm{GPa} / \mathrm{m}), \mathrm{J} 3-2$ and c) mixed initial normal stress $(1.0 \mathrm{MPa})$ and normal stiffness $(0.5 \mathrm{Gpa}), \mathrm{J} 3-3$. The white 'islands' show contact areas and the legend shows the order of transmissivity $\left(\mathrm{m}^{2} / \mathrm{sec}\right)$. 

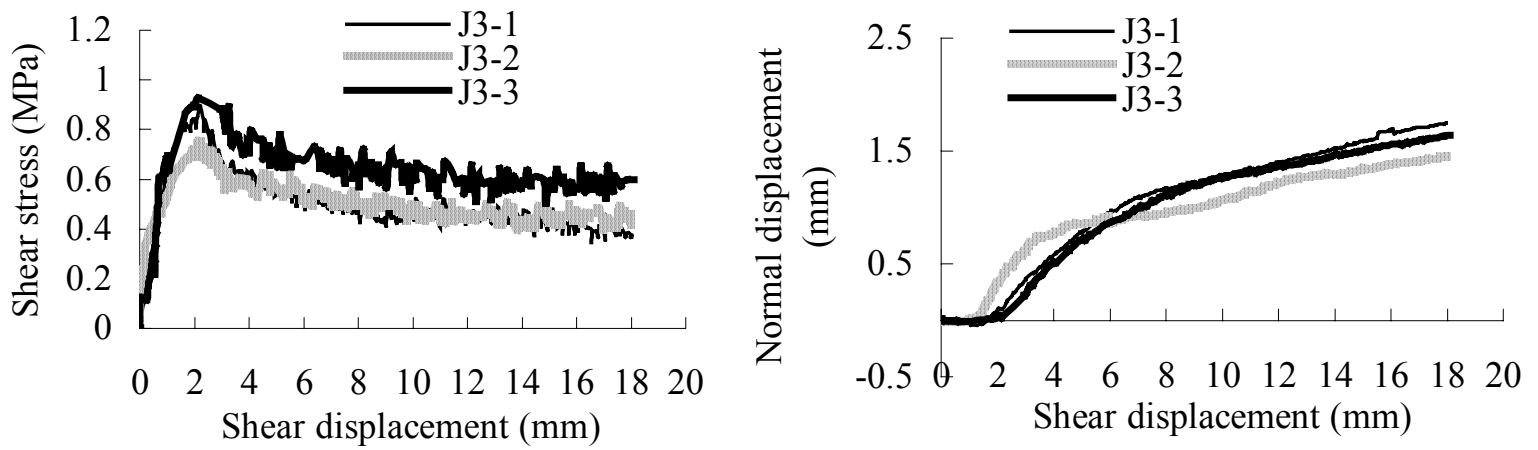

Fig. 5. Direct shear test results on sample J3: a) the shear stress versus shear displacement and b) the normal displacement versus shear displacement $[6,7]$. 


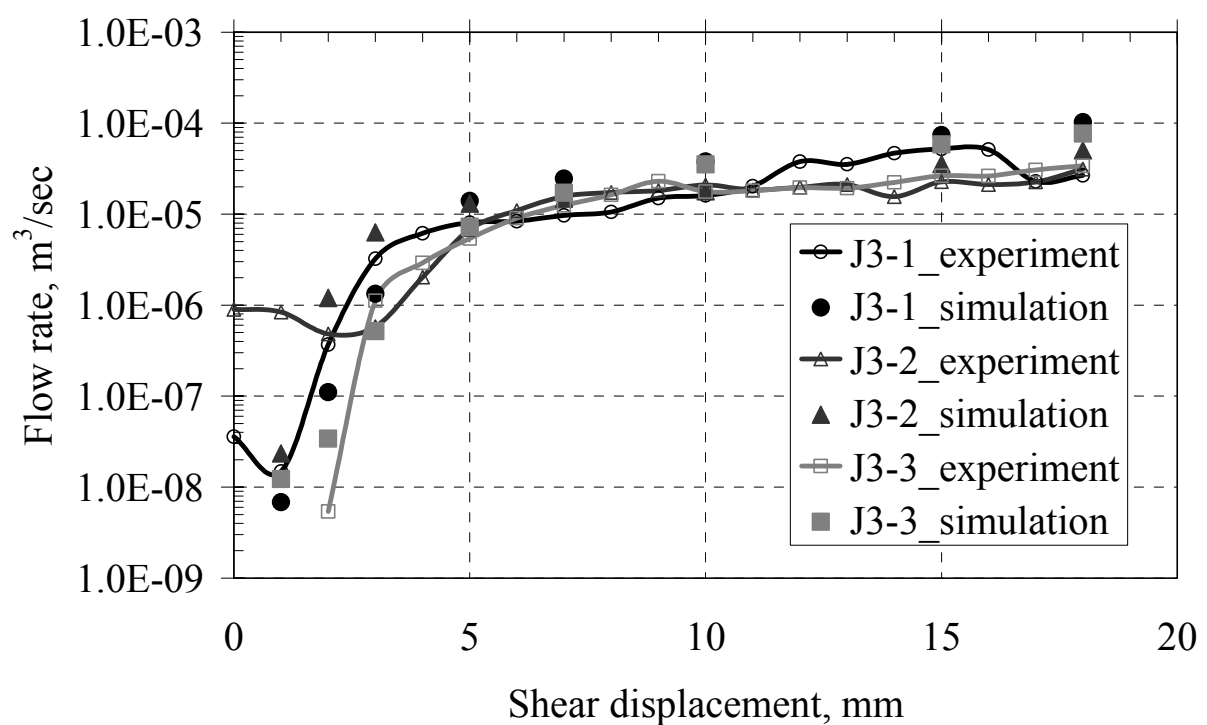

Fig. 6. Comparison of the flow rates at the outlet between laboratory experiments and numerical predictions for fracture sample $\mathrm{J} 3$ under different normal loading conditions $\mathrm{J} 3-1$, J3-2 and J3-3. It should be noted that zero flow rate values cannot be plotted in the log scale of the flow rate axis, which was assumed at the initial shear stages of modeling. 


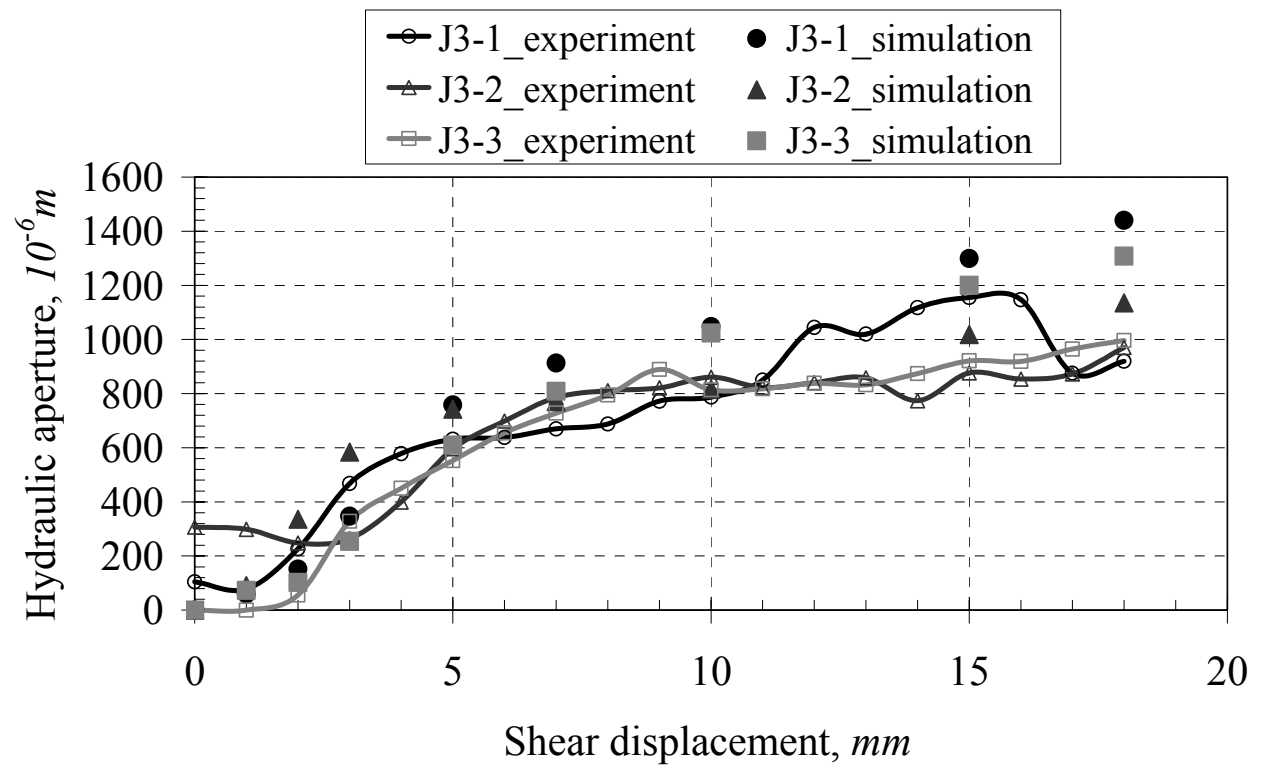

Fig. 7. Comparison of hydraulic apertures back calculated from the flow rates obtained from the experiments (assuming the cubic law) and numerical simulations for sample $\mathrm{J} 3$ under different normal loading conditions $\mathrm{J} 3-1, \mathrm{~J} 3-2$ and $\mathrm{J} 3-3$. 


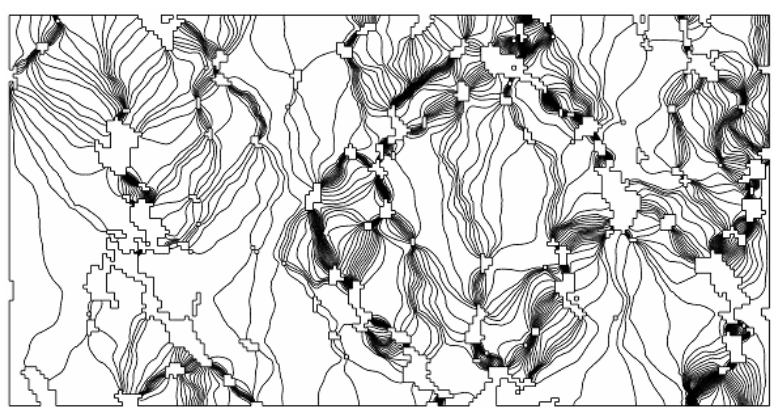

a)

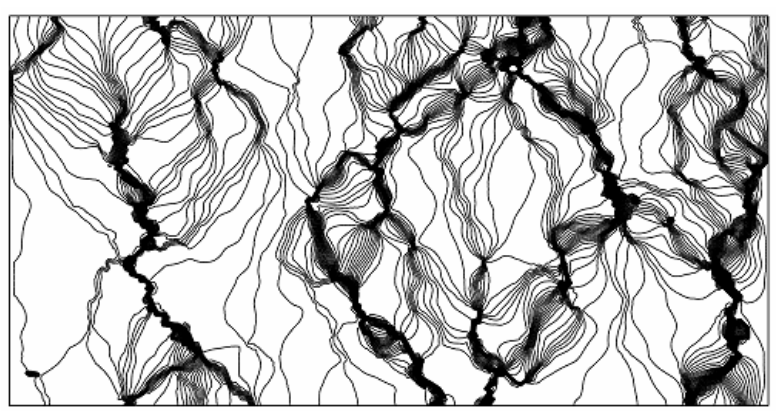

b)

Fig. 8. Iso-value counters of hydraulic head at $5 \mathrm{~mm}$ shear displacement a) with and b), without special treatment for contact areas for fracture sample $\mathrm{J} 3$ under constant normal stress of $1 \mathrm{MPa}, \mathrm{J} 3-1$. Iso-value counters were drawn from $2.5 \mathrm{e}-4 \mathrm{~m}$ to $9.975 \mathrm{e}-2 \mathrm{~m}$ with every $0.5 \mathrm{e}-4 \mathrm{~m}$ intervals. It should be noted that very small aperture value of $0.1 \mu \mathrm{m}$ was given for contact elements for the case of without special treatment. 